\title{
Follicle-stimulating hormone increases primordial follicle reserve in mature female hypogonadal mice
}

\author{
C M Allan, Y Wang ${ }^{1}$, M Jimenez, B Marshan, J Spaliviero, \\ P Illingworth ${ }^{1}$ and $\mathbf{D}$ J Handelsman
}

Andrology Laboratory, ANZAC Research Institute, University of Sydney, Concord Hospital, New South Wales 2139, Australia

${ }^{1}$ Department of Reproductive Medicine, Westmead Hospital, University of Sydney, New South Wales 2145, Australia

(Requests for offprints should be addressed to C M Allan; Email: charles@anzac.edu.au)

\begin{abstract}
Ovarian primordial follicle reserve is considered hormonally independent or subject to depletion by FSHdriven follicle recruitment. To explore specific in vivo effects of FSH on early follicle populations in the absence of luteinizing hormone (LH) activity, we examined mature hypogonadal $(h p g)$, gonadotrophin-deficient mice expressing transgenic (tg) human FSH. Sustained expression of tg-FSH $(5 \cdot 3 \pm 0 \cdot 3 \mathrm{IU} / \mathrm{l})$ increased ovary weights fourfold and significantly elevated total primordial follicle numbers twofold in tg-FSH hpg $(4209 \pm 457)$ relative to non-tg $h p g(2079 \pm 391)$ and wild-type $(2043 \pm 195)$ age-matched ovaries. Absolute primary follicle numbers in tg-FSH $h p g$ ovaries were similar to non-tg $h p g$ and wild-type ovaries. Furthermore, tg-FSH quantitatively increased secondary and antral follicles in $h p g$ ovaries
\end{abstract}

to numbers equivalent to wild-type, but did not induce ovulation, indicating a selective FSH response without LH. Circulating inhibin B and inhibin A levels were significantly increased in tg-FSH $h p g$ females compared with $h p g$ controls, and inhibin B correlated with antral number, consistent with FSH-driven antral follicle formation. These findings revealed that sustained pituitaryindependent FSH activity, in the absence of endogenous gonadotrophins, promotes an increase in primordial follicle reserve despite also stimulating follicular growth in mature females. Therefore, the tg-FSH $h p g$ ovary presents a novel paradigm to evaluate specific gonadotrophin effects on follicle reserve and recruitment.

Journal of Endocrinology (2006) 188, 549-557

\section{Introduction}

Follicle-stimulating hormone (FSH) is critical for ovarian folliculogenesis and female fertility. FSH plays a key role in antral follicle development and, in combination with luteinizing hormone (LH), stimulates preovulatory follicular growth (reviewed in McGee \& Hsueh 2000, Hillier 2001). In contrast, the primordial follicles are generally thought to be FSH-independent. Primordial follicles are present and develop up to the late preantral stage in the ovaries of mice lacking functional gonadotrophinreleasing hormone $(\mathrm{GnRH})$ (Halpin et al. 1986, Allan et al. 2001), FSH beta-subunit (Kumar et al. 1997) or FSH receptor (Dierich et al. 1998, Abel et al. 2000).

While small preantral follicular development may occur independently of FSH, the total number of early growing follicles is increased by FSH action (Halpin \& Charlton 1988, McGee et al. 1997, Oktay et al. 1998). Furthermore, FSH-mediated follicle growth may also indirectly accelerate the age-dependent depletion of the finite primordial pool initially established after birth. For example, increased basal serum FSH in young adult rats after unilateral ovariectomy is associated with an increased loss of primordial follicles (Meredith et al. 1992, Anzalone et al. 2001). Advancing our understanding of FSH effects on ovarian development and its capacity to regulate early folliculogenesis has implications for follicle preservation and/or recovery during or after chemotherapy (Blumenfeld 2002) or in vitro fertilization (IVF) treatment (Huirne et al. 2004), or for the relationship between elevated FSH and follicle depletion during human reproductive ageing (Hansen et al. 2005), particularly in light of the potential for sustained primordial follicle renewal throughout life (Johnson et al. 2004). However, investigating the direct, selective in vivo effects of FSH in the ovary is difficult in human subjects, while suitable animal models are limited.

For selective examination of gonadal FSH actions, we previously generated transgenic (tg) mice that express human FSH independently of GnRH (Allan et al. 2001). This features pituitary-independent tg-FSH expression, which, when combined with the gonadotrophindeficient background of hypogonadal $(h p g)$ mice, allows investigation of FSH activity in isolation of $\mathrm{LH}$ effects 
(Allan et al. 2001, 2004). The hpg mouse is complementary to models with selective disruption of LH-beta (Ma et al. 2004) or receptor (Lei et al. 2001, Zhang et al. 2001) genes, although free from secondary effects on FSH secretion that confound interpretation of the later model of permanent LH insensitivity. The immature ovaries of hpg females exhibit follicle arrest at the preantral stage but remain hormonally responsive (Halpin et al. 1986, Allan et al. 2001). We previously showed that tg-FSH dosedependently increased ovary weights and circulating inhibin B levels in hpg mice (Allan et al. 2001). This tg-FSH $h p g$ paradigm is now used to explore the effect of FSH upon follicle dynamics in young, mature females, revealing unexpected upregulation by FSH of the primordial follicle stock.

\section{Materials and Methods}

\section{Transgenic FSH mice}

Transgenic $\alpha \beta .6$ mice expressing human (h)FSH (tg-FSH) independently of $\mathrm{GnRH}$ were previously described (Allan et al. 2001). Females expressing tg-FSH on a gonadotrophin-deficient hypogonadal background $\left(G n r h 1^{-1-}\right)$ were obtained by crossing tg animals heterozygous for the Gnrh1 gene deletion $\left(\right.$ Gnrh $\left.^{+/-}\right)$as determined by detection of wild-type or disrupted Gnrh1 gene or tg PCR products, as previously described (Singh et al. 1995, Allan et al. 2001). Animals were housed under controlled conditions (12-h light-dark cycle, $\left.19-22^{\circ} \mathrm{C}\right)$ with free access to food and water. Mature mice (9-11 weeks old) were used for ovary collection. Littermates or

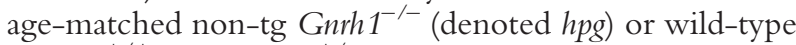
$\left(\right.$ Gnrh $1^{+/+}$or Gnrh $\left.1^{+/-}\right)$females served as controls. Animal procedures were approved by the University of Sydney animal ethics committee and performed in accordance with the National Health and Medical Research Council Code of Practice for the Care and Use of Animals and the NSW Animal Research Act 1985. Blood was collected from terminally anaesthetized mature females, and serum was stored at $-20{ }^{\circ} \mathrm{C}$.

\section{Serum hormone assays}

Serum hormone levels were measured in duplicate in all assays. Serum levels of human FSH were determined by species-specific, two-site immunofluorometric assay as previously described (Allan et al. 2001). Inhibin A and B levels were determined with human inhibin assays and serially diluted mouse follicle culture media as standard (Wang et al. 2005). Inhibin levels were interpolated from mouse standards, using arbitrary units $(\mathrm{AU} / \mathrm{ml})$ to avoid non-parallelism between human standards and mouse samples (Wang et al. 2005). Detection limits for inhibin A and $\mathrm{B}$ were $7 \cdot 8$ and $8.0 \mathrm{AU} / \mathrm{ml}$ respectively.

\section{Ovary fixation and follicle counting}

Ovaries were removed and incubated overnight in $4 \%$ paraformaldehyde in PBS ( $\mathrm{pH} 7 \cdot 4$ ), washed with $70 \%$ ethanol and then embedded in hydroxymethylmethacrylate resin (Technovit 7100; Kulzer, Friedrichsdorf, Germany) as recommended by the manufacturer. With one ovary per mouse, tissue sections were cut with the Polycut S microtome (Reichert Jung, Nossloch, Germany). Thin sections $(5 \mu \mathrm{m})$ were stained with $0.5 \%$ toluidine blue, and thick sections $(25 \mu \mathrm{m})$ for follicle counting were consecutively stained with periodic acidSchiff, haematoxylin and Scott's blue solution. Morphological identification and estimation of total primordial (oocytes with partial or complete layer of squamous granulosa cells (Meredith et al. 2000)), primary (single layer of cuboidal granulosa cells), secondary (two or more layers of cuboidal granulosa cells but no visible antrum), or antral (one or multiple visible fluid filled antral cavities) follicles were performed with a light microscope with microcator to monitor section depth and CAST-GRID software (Olympus, Albertslund, Denmark). Follicle nuclei (primordial) or nucleoli (primary-antral) were used as reference counting points. In serial sections, the first sections were selected randomly, then all primordial and primary follicles were counted ( $\times 40$ oil objective) to a depth of $18 \mu \mathrm{m}$ in every fourth $25 \mu \mathrm{m}$ section, and then whole ovary estimates were calculated by Cavalieri's principle and accounting for section $(\times 4 / 1)$ and depth $(\times 25 / 18)$ sampling. Section areas flanking the $18 \mu \mathrm{m}$ counting depth allowed confirmation of follicle classification (e.g. primordial vs primary) to avoid potential capping effects. Total secondary and antral follicle numbers were counted in every $25 \mu \mathrm{m}$ serial section from each ovary ( $\times 10$ objective).

\section{Statistical analysis}

Statistical analysis was performed with SigmaSat statistical software (SPSS Version 11.0; Chicago, IL, USA). Data were analysed by unpaired $t$-test, Fisher's test, Pearson correlation or one-way ANOVA; significance (differences, linear association) was defined as $P<0 \cdot 05$. Samples with undetectable hormones were assigned zero. Alternative assignment to detection limit values did not alter any significant difference observed. All data are presented as mean \pm S.E.M

\section{Results}

\section{Body and ovary weights}

Body weights of 9-11-week-old tg-FSH and non-tg hpg females were equivalent, but reduced (15-18\%) in comparison to age-matched, non-tg, wild-type controls (Fig. 1). Compared with $h p g$ controls, the tg-FSH hpg females 


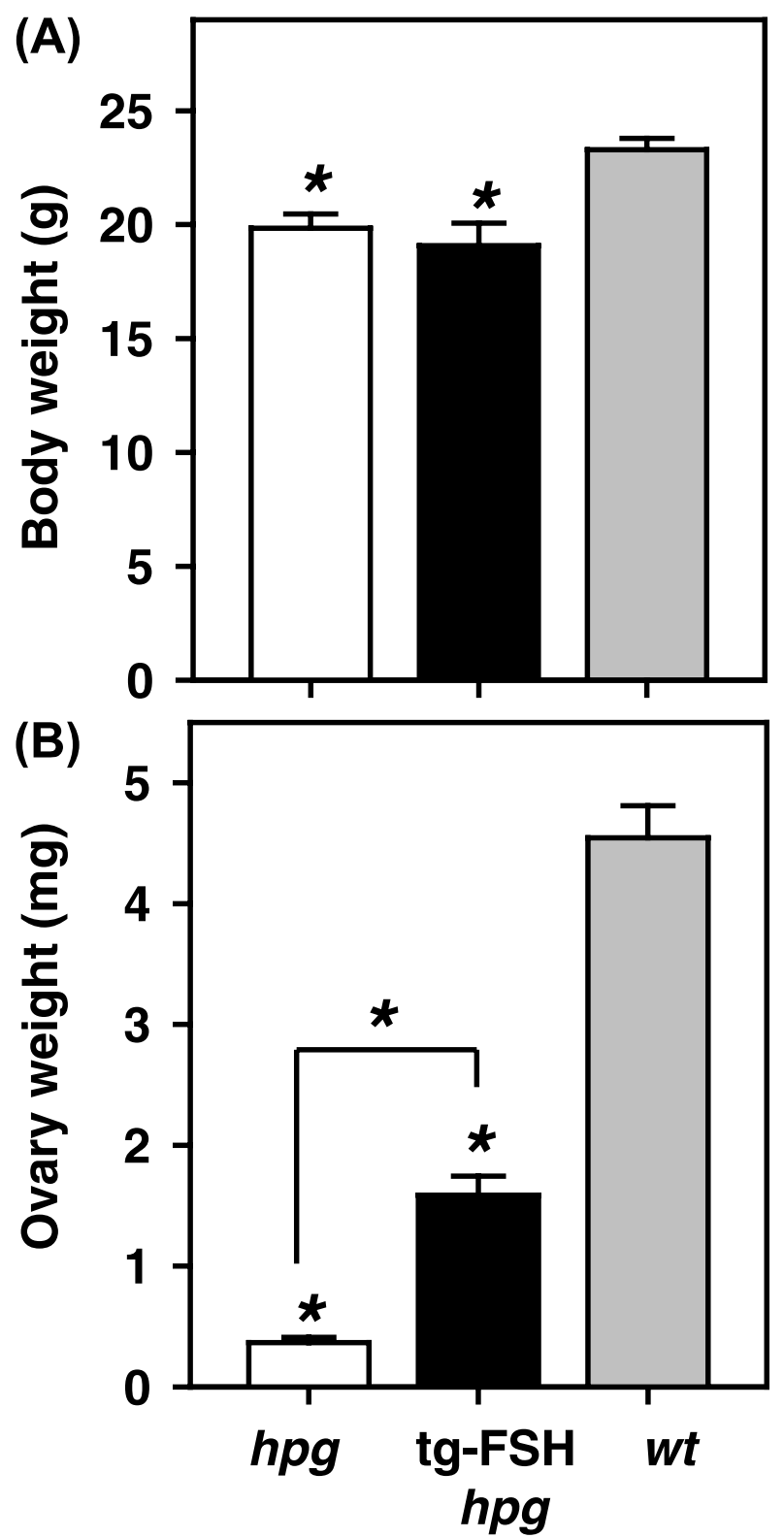

Figure 1 Body (A) and left ovary (B) weights of non-tg ( $n=14$, white bars) or tg-FSH hpg ( $n=17$, black bars) females, as well as corresponding data for age-matched, non-tg, wild-type females $(n=7$, grey bars) for comparison. Significant differences from wild-type are indicated, ${ }^{*} P<0 \cdot 05$.

exhibited significantly increased ovary weights (fourfold), which remained threefold smaller than wild-type age-matched ovaries (Fig. 1).

\section{Ovary histology}

Qualitative histological examination of non-tg $h p g$ ovaries from 9-11-week-old females showed follicular development progressed beyond primary follicle stage, and sparse numbers of early antral follicles were detected, as shown in Fig. 2. Examination of tg-FSH $h p g$ ovaries revealed that follicular development had progressed to advanced antral stage, as Fig. 2 shows. No corpora lutea were observed in any tg-FSH or non-tg hpg ovary examined.

\section{Follicle numbers}

Total primordial follicle numbers in 9-11-week-old tg-FSH hpg females were significantly higher (twofold, $P<0 \cdot 05)$ than in both non-tg hpg and wild-type females. The total number of primordial follicles was equivalent in age-matched, gonadotrophin-deficient $h p g$ relative to wild-type ovaries (Fig. 3). The absolute number of primary follicles in tg-FSH $h p g$ ovaries was not significantly different from non-tg $h p g$ or wild-type ovaries (Fig. 3). However, secondary follicles were significantly increased $(P<0.001)$ and restored to normal levels in tg-FSH hpg mice (Fig. 3), although the total number of secondary ovarian follicles in $h p g$ mice was only $25 \%$ of wild-type numbers. Non-tg hpg control ovaries contained limited numbers of early antral follicles with small emerging antral spaces, and total antral follicle numbers of just $4.5 \%$ of wild-type numbers. Expression of tg-FSH significantly increased $(P<0 \cdot 001)$ total antral follicles more than 15-fold compared with non-tg hpg controls, restoring numbers to wild-type levels (Fig. 3).

\section{Hormone levels}

Mature (9-11-week-old), transgenic, $\alpha \beta .6$ line $h p g$ females expressed serum hFSH levels of $5 \cdot 4 \pm 0 \cdot 2$ IU/1 $(n=14)$, whereas non-tg females had undetectable hFSH levels consistent with previous findings (Allan et al. 2001).

Serum inhibin B was detectable $(\geq 8.0 \mathrm{AU} / \mathrm{ml})$ in significantly more tg-FSH (14/14) than non-tg (3/16) hpg females $(P<0 \cdot 001$, Fisher's test), and tg-FSH hpg mice had significantly higher $(P<0.001)$ serum inhibin B levels (Fig. 4). There was no difference between serum inhibin $\mathrm{B}$ levels in tg-FSH hpg and mature, wild-type females. Furthermore, there was a significant correlation between inhibin B levels and secondary and antral follicle numbers in the tg and non-tg $h p g$ ovaries examined, whereas there was no correlation with primordial and primary follicle numbers (Fig. 5). Partial regression showed that the strongest inhibin B relationship was with the antral follicles and that the relationship with secondary follicles was derived from that with antral follicles.

Likewise, serum inhibin A was detected $(\geq 7 \cdot 8 \mathrm{AU} / \mathrm{ml})$ in significantly more tg-FSH $(10 / 14)$ than non-tg $(2 / 16)$ $h p g$ females $(P<0 \cdot 005$, Fisher's test), and mean levels of serum inhibin A were significantly higher $(P<0 \cdot 05)$ in the tg-FSH group (Fig. 4). Serum inhibin A levels were lower in tg-FSH hpg than in mature, wild-type females, and there was no correlation between serum inhibin A and 


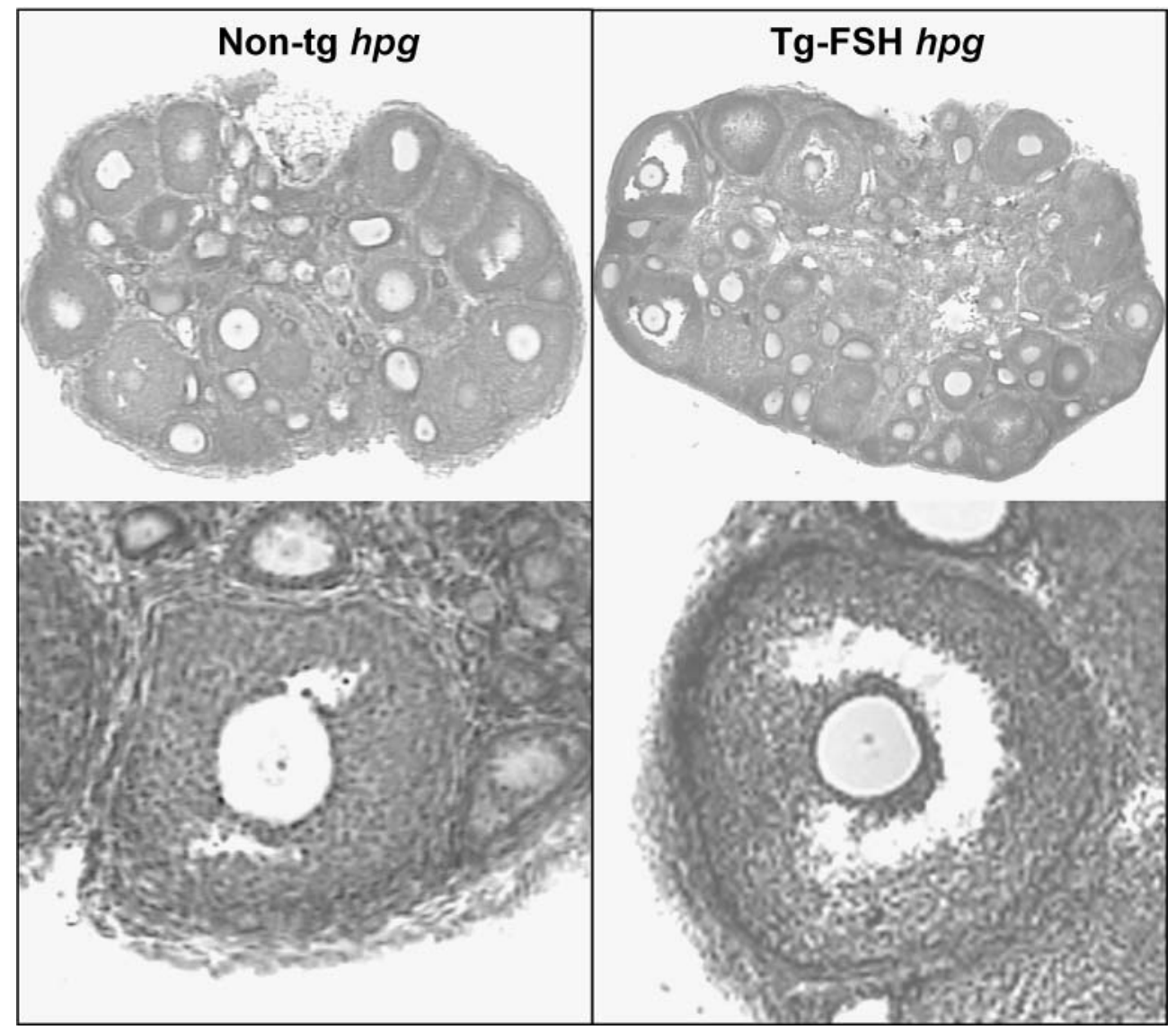

Figure 2 Ovarian development in tg-FSH hpg female mice. Left panels show a typical ovary section and maximal level of follicle development observed in non-tg hpg control females, which exhibited few follicles with very early antral cavity formation, as shown below. The right panels demonstrate the folliculogenesis and maximal antral follicle development found in tg-FSH hpg ovaries.

different follicle types present in the tg and non-tg $h p g$ ovaries examined (data not shown).

\section{Discussion}

We have investigated the potential effect of FSH upon early follicle dynamics, using a mouse model exhibiting isolated FSH-driven follicle development. Transgenic expression of pituitary-independent $\mathrm{FSH}$ in gonadotrophin-deficient $h p g$ mice allowed the selective in vivo investigation of the FSH ovarian response in the absence of LH activity. Unexpectedly, primordial follicle numbers were higher in tg-FSH hpg than non-tg hpg females, suggesting that FSH may have a role in the positive regulation of ovarian primordial follicle reserve.

Total primordial follicle numbers in tg-FSH hpg mice were also greater than the numbers in age-matched wild-type mice, suggesting that tg-FSH activity increased the overall development and/or survival of primordial follicles. The precise mechanism of the FSH-stimulated increase in total primordial follicles in tg $h p g$ ovaries remains undefined, but may involve increased initial accrual, decreased atresia or reduced developmental progression of the primordial follicle population. The observation of equivalent numbers of primordial follicles in mature non-tg hpg and wild-type ovaries is consistent with an early report of similarly 'non-growing' follicle numbers in immature and adult $h p g$ and wild-type mice (Halpin et al. 1986). Mouse primordial follicle numbers are maximal during early postnatal development (Peters 1969, Hirshfield 1991, Johnson et al. 2004) and thereafter rapidly decline via atresia (Faddy et al. 1983, 1987, McGee \& Hsueh 2000). Therefore, the larger primordial pool in mature tg-FSH hpg ovaries relative to normal (or non-tg $h p g$ ) may reflect a reduced rate of atresia. Alternatively, the rate at which primordial follicles enter the growth phase may be reduced in $\operatorname{tg} h p g$ mice by the presence of more secondary/antral follicles (Faddy et al. 1987). However, we did not observe decreased numbers of downstream 


\section{Total follicle numbers / ovary}
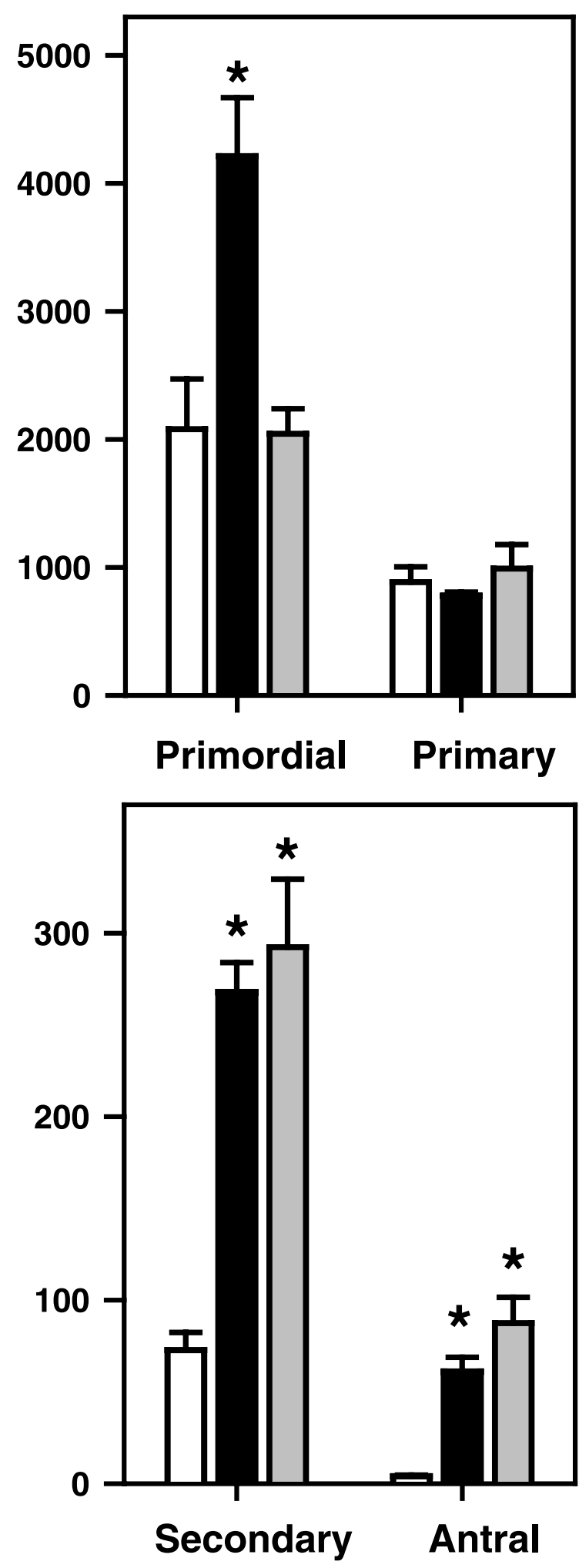

primary follicles in tg hpg ovaries compared with controls, consistent with studies in hpg females treated with exogenous FSH for 4-20 days (Halpin \& Charlton 1988, Wang et al. 2005). Instead, primary follicle numbers were equivalent to controls, suggesting that reduced primordial recruitment may not explain our results.

Another possibility is that perinatal formation of the primordial population may be enhanced in tg-FSH hpg mice. Although this stage was considered FSHindependent due to minimal FSH binding (Dunkel et al. 1994) or responsiveness (Peters et al. 1973, Sokka \& Huhtaniemi 1990) and absence of full-length FSH receptor mRNA (Dunkel et al. 1994, Rannikki et al. 1995, O'Shaughnessy et al. 1996) in perinatal mouse or rat ovaries, recent studies suggest that FSH activity may regulate early folliculogenesis before the arrival of laterstage, FSH-dependent growing antral follicles. In hamsters, an early role for FSH in folliculogenesis is suggested by reduced primordial follicle formation after treatment of mothers with FSH-antiserum during late gestation, and expression of full-length FSH receptor mRNA in the fetal ovary as early as day 13 of gestation (Roy \& Albee 2000). Neonatal (2-day-old) mice genetically lacking functional FSH receptor exhibit reduced numbers of early, non-growing follicles (Balla et al. 2003). Furthermore, FSH receptor mRNA transcripts are present in 1-5- day-old mouse ovaries (O'Shaughnessy et al. 1996), 3-day-old rat ovaries (Dunkel et al. 1994) and human early preantral follicles (Oktay et al. 1997). Our data combined with the above observations challenge the view of gonadotrophin-independent early folliculogenesis and suggest that FSH activity can significantly influence the primordial and early preantral follicle populations. Whether or not tg-FSH in our model has direct effects on early follicles during (or after) primordial formation, or progressive indirect actions through the growing follicle populations over time remains to be determined. Future analysis of primordial follicle dynamics in postnatal and ageing tg hpg mice will enhance our understanding of this unexpected primordial follicular response to FSH.

In contrast to the normal primordial numbers found in hpg ovaries, hypophysectomized (Meredith et al. 1986) or GnRH-antagonist treated (Meijs-Roelofs et al. 1990) rats exhibit a decreased rate of loss of primordial follicles, resulting in higher than normal primordial follicle numbers. The different primordial numbers found in these gonadotrophin-deficient mouse and rat models remains an enigma. One notable difference between

Figure 3 Total ovarian follicle populations in non-tg $(n=8$, white bars) or tg-FSH hpg ( $n=12$, black bars) females, as well as follicle numbers in age-matched, non-tg, wild-type ovaries $(n=6$, grey bars) for comparison, quantified, as described in Materials and Methods. Significant differences relative to hpg are indicated, ${ }^{*} P<0 \cdot 05$. 

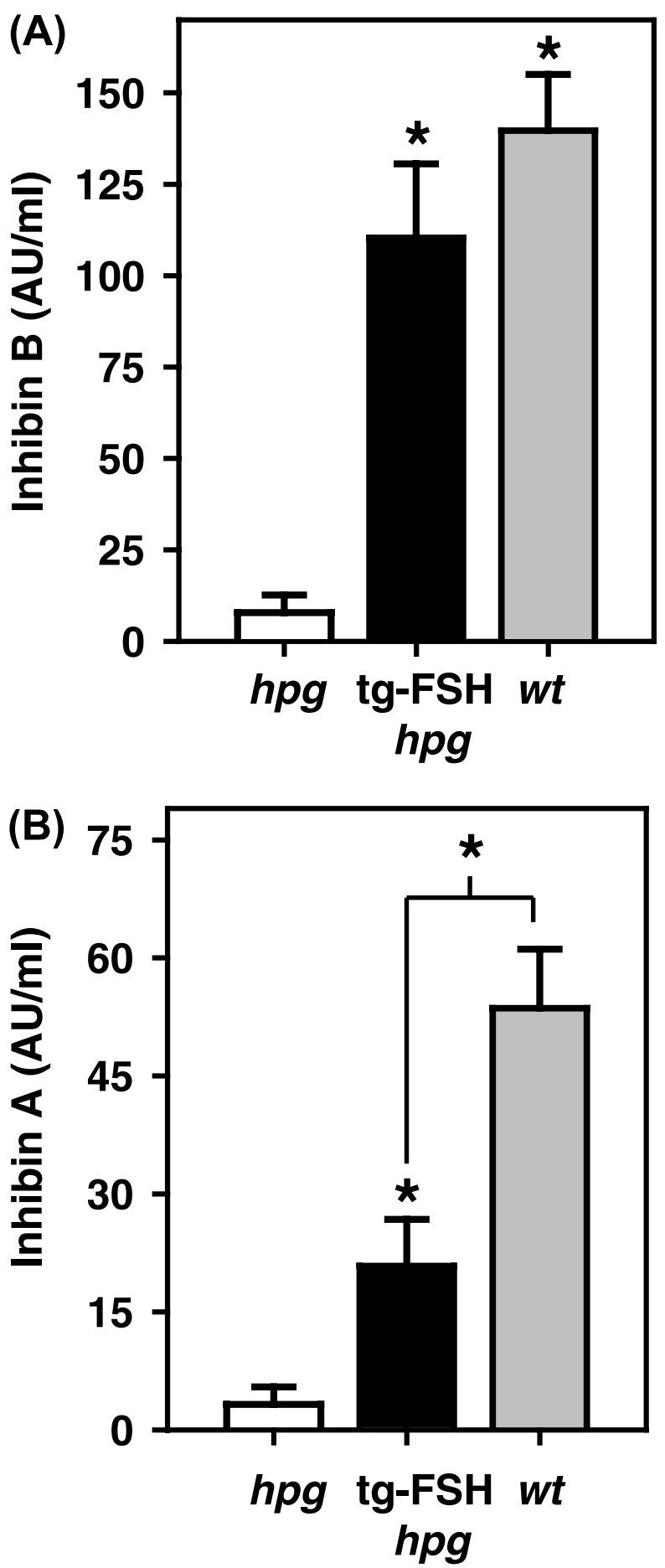

Figure 4 Serum inhibin $B(A)$ and inhibin $A(B)$ levels in the tg-FSH ( $n=14$, black bars) and non-tg ( $n=16$, white bars) hpg female mice are shown as arbitrary units, as described in Materials and Methods. For comparison, serum inhibin A and B levels in mature, wild-type females $(n=7$, grey bars) are shown. Significant differences from $h p g$ are indicated, ${ }^{*} P<0 \cdot 05$. the hpg mouse and classical rat models is the delayed postnatal loss of gonadotrophins in 21-day-old hypophysectomized or 6-15-day-old GnRH-antagonist-treated rats, compared with congenital FSH/LH absence in $h p g$ mice. Complete absence of postnatal FSH in hpg mice may account for the decreased primordial stock relative to the above rat models. In the present study, tg-FSH expression is driven by the rat insulin II gene promoter that confers postnatal expression of heterologous transgenes (Epstein et al. 1992, Takamura et al. 1998), as confirmed by equivalent serum tg-FSH levels in 10-dayold mice (data not shown). Therefore, the tg-hpg model will provide FSH expression during the important postnatal period of follicular development, unlike previous studies of short-term exogenous FSH actions in $h p g$ females only after complete postnatal gonadotrophin deficiency (Halpin \& Charlton 1988, Wang et al. 2005).

Our tg-hpg model has provided direct evidence that FSH activity in the absence of LH may markedly affect the development, survival or recruitment of the early follicle population. Previous work showed that mice overexpressing tg $\mathrm{LH}$ exhibited an accelerated loss of primordial follicles despite the presence of FSH (Flaws et al. 1997). Therefore, increased numbers of primordial follicles in tg-FSH $h p g$ females may also reflect the absence of an opposing LH effect on the resting primordial follicle pool. Despite the lack of LH activity in $h p g$ ovaries, the expression of tg-FSH increased secondary and stimulated antral follicle development, confirming previous in vivo studies demonstrating that antral follicle development is highly regulated by FSH (Halpin \& Charlton 1988, Wang \& Greenwald 1993, Kumar et al. 1997, McGee et al. 1997, Dierich et al. 1998, Oktay et al. 1998, Abel et al. 2000).

Increased serum levels of inhibin B and inhibin A in tg-hpg females demonstrated that tg-FSH stimulated ovarian inhibin secretion (reviewed in Findlay et al. 2001). Elevated inhibin B supports our previous work showing that $\operatorname{tg}-\mathrm{FSH}$ dose-dependently increased circulating inhibin B in hpg females (Allan et al. 2001), and confirming the accepted role of FSH in stimulating granulosa cell inhibin B expression. Furthermore, our present work showed a significant correlation between serum inhibin B and predominantly the antral follicle populations. Likewise, elevated circulating inhibin A in tg-FSH $h p g$ mice exhibiting antral follicle development, relative to non-tg hpg controls with antral arrest, agrees with the reported rise of inhibin A expression in secondary and antral follicles (Meunier et al. 1988, Wang et al. 2005). Inhibin A detection in $71 \%$ of tg-FSH (LH-deficient) $h p g$ females in this study was similar to the $63 \%$ of LHR-null females expressing detectable inhibin A found by Hirst et al. (2004). Overall, these findings support recent studies showing increased serum inhibins B and A in FSH-treated hpg females to be associated with antral follicles, although higher inhibin A requires LH activity and the presence of preovulatory follicles (Wang et al. 2005). 


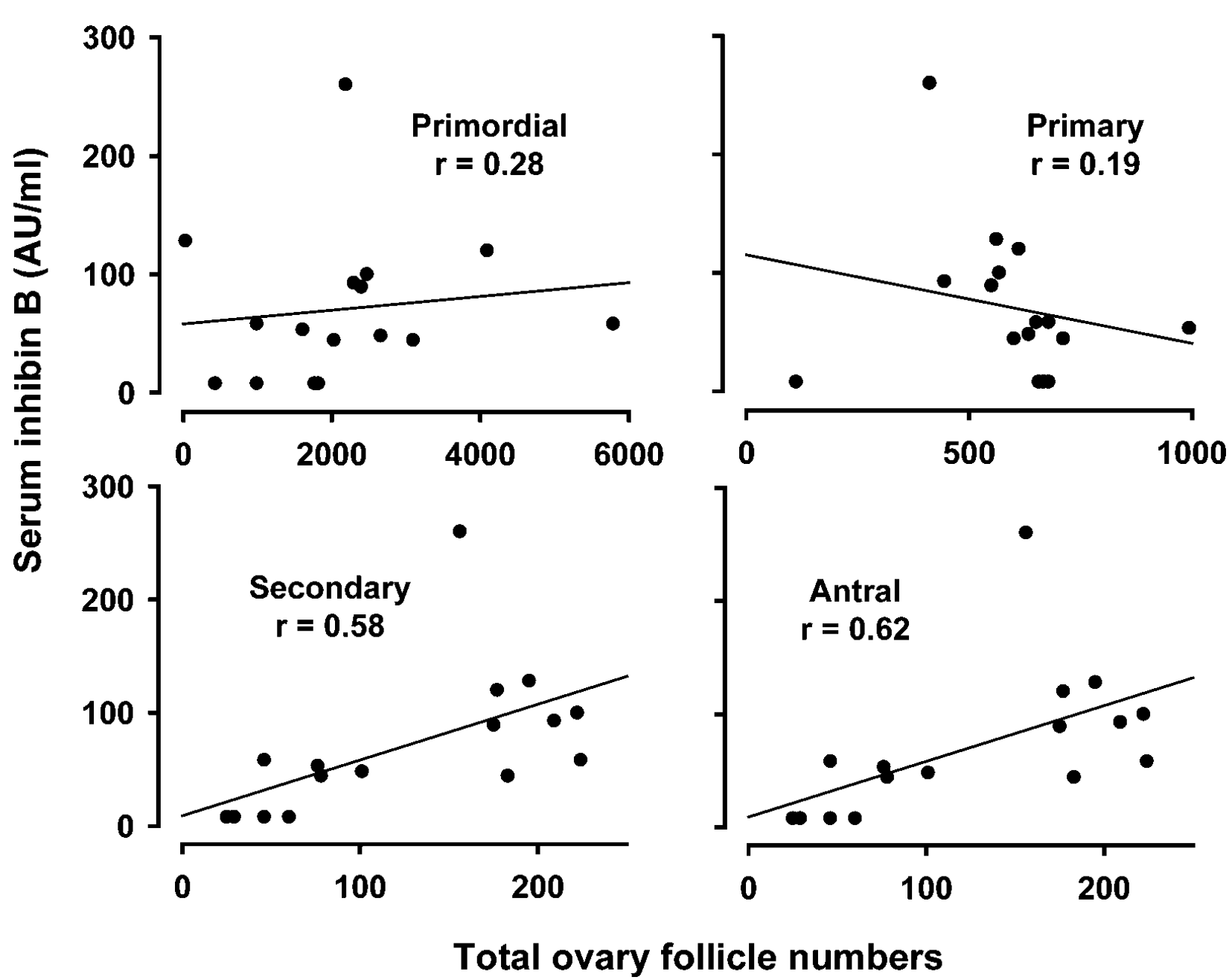

Figure 5 Correlations between the relative inhibin B levels and the absolute numbers of different follicle types found in corresponding tg and non-tg hpg females $(n=16)$. Serum inhibin B levels were significantly correlated to the numbers of secondary $(P=0 \cdot 017)$ and antral $(P=0.011)$ follicles per ovary, but not the primordial $(P=0 \cdot 287)$ or primary $(P=0 \cdot 475)$ populations.

The tg-FSH hpg ovary without LH stimulation would be expected to resemble ovaries in mice lacking functional LH-beta or receptor genes (Lei et al. 2001, Zhang et al. 2001, Ma et al. 2004), which previously provided valuable comparisons for testicular development (Zhang et al. 2001, Allan et al. 2004, Hirst et al. 2004). Indeed, arrested antral follicle development was observed in all these models exhibiting isolated FSH activity. Mice congenitally lacking the LH receptor exhibit elevated circulating gonadotrophins (Lei et al. 2001, Zhang et al. 2001) that are susceptible to steroidal regulation, which would complicate analysis of FSH actions combined with other hormones. In comparison, ectopic FSH expression in the tg-hpg model independent of GnRH and LH (Allan et al. 2004, Allan et al. 2001), as well as preserved hormone responsiveness, allows further investigation of FSH in isolation or combined with other hormones. The confounding effects of supraphysiological FSH concentrations previously reported in tg-FSH mice (Kumar et al. 1999) were not observed in this tg-FSH hpg model, since serum tg-FSH (4-5 IU/1) did not impede the fertility of young non-hpg females and was therefore within the limits compatible with physiological ovarian function (paper in preparation, Allan et al.).

In summary, our present study shows that FSH may enhance the early follicle stock. In isolation, tg-FSH activity increased the primordial pool relative to normal, despite predicted attrition through concurrent stimulation of antral follicle development and growth to the early preovulatory stage. Thus, the tg-FSH $h p g$ ovary provides a valuable platform for exploration of the underlying molecular mechanisms that may orchestrate the development, survival or progression of the primordial follicle population. Future studies using this novel tg-FSH 
paradigm will explore the functional consequences of combined LH or steroidal actions upon follicle dynamics.

\section{Acknowledgement}

We acknowledge the valued research assistance of the late Adam Koch.

\section{Funding}

This research was supported by funding from the National Health and Medical Research Council. The authors declare that there is no conflict of interest that would prejudice the impartiality of this scientific work.

\section{References}

Abel MH, Wootton AN, Wilkins V, Huhtaniemi I, Knight PG \& Charlton HM 2000 The effect of a null mutation in the follicle-stimulating hormone receptor gene on mouse reproduction. Endocrinology 141 1795-1803.

Allan CM, Haywood M, Swaraj S, Spaliviero J, Koch A, Jimenez M, Poutanen M, Levallet J, Huhtaniemi I, Illingworth P et al. 2001 A novel transgenic model to characterize the specific effects of follicle-stimulating hormone on gonadal physiology in the absence of luteinizing hormone actions. Endocrinology 142 2213-2220.

Allan CM, Garcia A, Spaliviero J, Zhang FP, Jimenez M, Huhtaniemi I \& Handelsman DJ 2004 Complete Sertoli cell proliferation induced by follicle-stimulating hormone (FSH) independently of luteinizing hormone activity: evidence from genetic models of isolated FSH action. Endocrinology 145 1587-1593.

Anzalone CR, Hong LS, Lu JK \& LaPolt PS 2001 Influences of age and ovarian follicular reserve on estrous cycle patterns, ovulation, and hormone secretion in the Long-Evans rat. Biology of Reproduction 64 1056-1062.

Balla A, Danilovich N, Yang Y \& Sairam MR 2003 Dynamics of ovarian development in the FORKO immature mouse: structural and functional implications for ovarian reserve. Biology of Reproduction 69 1281-1293.

Blumenfeld Z 2002 Preservation of fertility and ovarian function and minimalization of chemotherapy associated gonadotoxicity and premature ovarian failure: the role of inhibin-A and -B as markers. Molecular and Cellular Endocrinology 187 93-105.

Dierich A, Sairam MR, Monaco L, Fimia GM, Gansmuller A, LeMeur M \& Sassone-Corsi P 1998 Impairing follicle-stimulating hormone (FSH) signaling in vivo: targeted disruption of the FSH receptor leads to aberrant gametogenesis and hormonal imbalance. PNAS 95 13612-13617.

Dunkel L, Tilly JL, Shikone T, Nishimori K \& Hsueh AJ 1994 Follicle-stimulating hormone receptor expression in the rat ovary: increases during prepubertal development and regulation by the opposing actions of transforming growth factors beta and alpha. Biology of Reproduction 50 940-948.

Epstein PN, Boschero AC, Atwater I, Cai X \& Overbeek PA 1992 Expression of yeast hexokinase in pancreatic beta cells of transgenic mice reduces blood glucose, enhances insulin secretion, and decreases diabetes. PNAS 89 12038-12042.

Faddy MJ, Gosden RG \& Edwards RG 1983 Ovarian follicle dynamics in mice: a comparative study of three inbred strains and an F1 hybrid. Journal of Endocrinology 96 23-33.
Faddy MJ, Telfer E \& Gosden RG 1987 The kinetics of pre-antral follicle development in ovaries of CBA/Ca mice during the first 14 weeks of life. Cell Tissue Kinetics 20 551-560.

Findlay JK, Drummond AE, Dyson M, Baillie AJ, Robertson DM \& Ethier JF 2001 Production and actions of inhibin and activin during folliculogenesis in the rat. Molecular and Cellular Endocrinology $180139-144$.

Flaws JA, Abbud R, Mann RJ, Nilson JH \& Hirshfield AN 1997 Chronically elevated luteinizing hormone depletes primordial follicles in the mouse ovary. Biology of Reproduction 57 1233-1237.

Halpin DM \& Charlton HM 1988 Effects of short-term injection of gonadotrophins on ovarian follicle development in hypogonadal (hpg) mice. Journal of Reproduction and Fertility 82 393-400.

Halpin DM, Jones A, Fink G \& Charlton HM 1986 Postnatal ovarian follicle development in hypogonadal (hpg) and normal mice and associated changes in the hypothalamic-pituitary ovarian axis. Journal of Reproduction and Fertility 77 287-296.

Hansen KR, Thyer AC, Sluss PM, Bremner WJ, Soules MR \& Klein NA 2005 Reproductive ageing and ovarian function: is the early follicular phase FSH rise necessary to maintain adequate secretory function in older ovulatory women? Human Reproduction 20 89-95.

Hillier SG 2001 Gonadotropic control of ovarian follicular growth and development. Molecular and Cellular Endocrinology 179 39-46.

Hirshfield AN 1991 Development of follicles in the mammalian ovary. International Reviews in Cytology 124 43-101.

Hirst RC, Abel MH, Wilkins V, Simpson C, Knight PG, Zhang FP, Huhtaniemi I, Kumar TR \& Charlton HM 2004 Influence of mutations affecting gonadotropin production or responsiveness on expression of inhibin subunit mRNA and protein in the mouse ovary. Reproduction 128 43-52.

Huirne JA, Lambalk CB, van Loenen AC, Schats R, Hompes PG, Fauser BC \& Macklon NS 2004 Contemporary pharmacological manipulation in assisted reproduction. Drugs 64 297-322.

Johnson J, Canning J, Kaneko T, Pru JK \& Tilly JL 2004 Germline stem cells and follicular renewal in the postnatal mammalian ovary. Nature 428 145-150.

Kumar TR, Wang Y, Lu N \& Matzuk MM 1997 Follicle stimulating hormone is required for ovarian follicle maturation but not male fertility. Nature Genetics 15 201-204.

Kumar TR, Palapattu G, Wang P, Woodruff TK, Boime I, Byrne MC \& Matzuk MM 1999 Transgenic models to study gonadotropin function: the role of follicle-stimulating hormone in gonadal growth and tumorigenesis. Molecular Endocrinology 13 851-865.

Lei ZM, Mishra S, Zou W, Xu B, Foltz M, Li X \& Rao CV 2001 Targeted disruption of luteinizing hormone/human chorionic gonadotropin receptor gene. Molecular Endocrinology 15 184-200.

Ma X, Dong Y, Matzuk MM \& Kumar TR 2004 Targeted disruption of luteinizing hormone beta-subunit leads to hypogonadism, defects in gonadal steroidogenesis, and infertility. PNAS 101 17294-17299.

McGee EA \& Hsueh AJ 2000 Initial and cyclic recruitment of ovarian follicles. Endocrine Reviews 21 200-214.

McGee EA, Perlas E, LaPolt PS, Tsafriri A \& Hsueh AJ 1997 Follicle-stimulating hormone enhances the development of preantral follicles in juvenile rats. Biology of Reproduction 57 990-998.

Meijs-Roelofs HM, van Cappellen WA, van Leeuwen EC \& Kramer P 1990 Short- and long-term effects of an LHRH antagonist given during the prepubertal period on follicle dynamics in the rat. Journal of Endocrinology 124 247-253.

Meredith S, Kirkpatrick-Keller D \& Butcher RL 1986 The effects of food restriction and hypophysectomy on numbers of primordial follicles and concentrations of hormones in rats. Biology of Reproduction 35 68-73. 
Meredith S, Dudenhoeffer G, Butcher RL, Lerner SP \& Walls T 1992 Unilateral ovariectomy increases loss of primordial follicles and is associated with increased metestrous concentration of follicle-stimulating hormone in old rats. Biology of Reproduction 47 162-168.

Meredith S, Dudenhoeffer G \& Jackson K 2000 Classification of small type $\mathrm{B} / \mathrm{C}$ follicles as primordial follicles in mature rats. Journal of Reproduction and Fertility 119 43-48.

Meunier H, Cajander SB, Roberts VJ, Rivier C, Sawchenko PE, Hsueh AJ \& Vale W 1988 Rapid changes in the expression of inhibin alpha-, beta A-, and beta B-subunits in ovarian cell types during the rat estrous cycle. Molecular Endocrinology 2 1352-1363.

Oktay K, Briggs D \& Gosden RG 1997 Ontogeny of folliclestimulating hormone receptor gene expression in isolated human ovarian follicles. Journal of Clinical Endocrinology and Metabolism $823748-3751$.

Oktay K, Newton H, Mullan J \& Gosden RG 1998 Development of human primordial follicles to antral stages in SCID/hpg mice stimulated with follicle stimulating hormone. Human Reproduction 13 1133-1138.

O’Shaughnessy PJ, Dudley K \& Rajapaksha WR 1996 Expression of follicle stimulating hormone-receptor mRNA during gonadal development. Molecular and Cellular Endocrinology 125 169-175.

Peters H 1969 The development of the mouse ovary from birth to maturity. Acta Endocrinologica 62 98-116.

Peters H, Byskov AG, Lintern-Moore S, Faber M \& Andersen M 1973 The effect of gonadotrophin on follicle growth initiation in the neonatal mouse ovary. Journal of Reproduction and Fertility 35 139-141.

Rannikki AS, Zhang FP \& Huhtaniemi IT 1995 Ontogeny of follicle-stimulating hormone receptor gene expression in the rat testis and ovary. Molecular and Cellular Endocrinology 107 199-208.
Roy SK \& Albee L 2000 Requirement for follicle-stimulating hormone action in the formation of primordial follicles during perinatal ovarian development in the hamster. Endocrinology 141 4449-4456.

Singh J, O'Neill C \& Handelsman DJ 1995 Induction of spermatogenesis by androgens in gonadotropin-deficient (hpg) mice. Endocrinology 136 5311-5321.

Sokka T \& Huhtaniemi I 1990 Ontogeny of gonadotrophin receptors and gonadotrophin-stimulated cyclic AMP production in the neonatal rat ovary. Journal of Endocrinology 127 297-303.

Takamura T, Kato I, Kimura N, Nakazawa T, Yonekura H, Takasawa S \& Okamoto H 1998 Transgenic mice overexpressing type 2 nitric-oxide synthase in pancreatic beta cells develop insulin-dependent diabetes without insulitis. Journal of Biological Chemistry 273 2493-2496.

Wang XN \& Greenwald GS 1993 Hypophysectomy of the cyclic mouse. I. Effects on folliculogenesis, oocyte growth, and follicle-stimulating hormone and human chorionic gonadotropin receptors. Biology of Reproduction 48 585-594.

Wang Y, Newton H, Spaliviero JA, Allan CM, Marshan B, Handelsman DJ \& Illingworth PJ 2005 Gonadotropin control of inhibin secretion and the relationship to follicle type and number in the hpg mouse. Biology of Reproduction 73 610-618.

Zhang FP, Poutanen M, Wilbertz J \& Huhtaniemi I 2001 Normal prenatal but arrested postnatal sexual development of luteinizing hormone receptor knockout (LuRKO) mice. Molecular Endocrinology 15 172-183.

Received 14 December 2005

Accepted 19 December 2005

Made available online as an Accepted Preprint

21 December 2005 